\title{
Los nombres propios hispánicos en Camerún: entre aventura y globalización semiolingüística*
}

\author{
ZACHARIE HATOLONG BOHO \\ hatolong@yahoo.fr
}

Recepción: 27 de septiembre de 2014

Aprobación: 25 de noviembre de 2014

Forma de citar este artículo: Hatolong Boho, Z. (2015). Los nombres propios hispánicos en Camerún: entre aventura y globalización semiolingüística. Cuadernos de Lingüística Hispánica, 26, 89-102, Tunja: Uptc.

* Artículo de reflexión en el que se analiza parte de los datos estudiados en el marco de una tesis doctoral.

** Profesor titular de lengua española y lingüística hispánica en el Departamento de Lenguas Extranjeras, Universidad de Maroua (Camerún). 


\title{
Resumen
}

El objetivo de este artículo consiste en recoger y analizar los nombres propios hispánicos de persona y lugar que abundan en los escritos urbanos de Camerún. Se ha postulado que dichos antropónimos y topónimos son muestra de una migración o aventura de palabras españolas en Camerún, o de un proceso de globalización linguística. Más allá del código lingǘstico que se importa a tierras africanas, se trata de la universalización de la cultura hispánica, la cual emprende vías singulares para extenderse por el mundo.

Palabras clave: entorno gráfico, onomástica, aventura, globalización lingüística

\section{Hispanic proper names in Cameroon: between adventure and semiolinguistic globalization}

\begin{abstract}
The objective of this article consists in collecting and analyzing the Hispanic proper names of people and places, plentiful in urban writing in Cameroon. It is proposed that such anthroponyms and toponyms are a sample of an immigration or adventure of Spanish words into Cameroon, as well as part of a linguistic globalization process. Beyond the linguistic code imported by African lands, this phenomenon points to the globalization of Hispanic culture which is undergoing unique ways to extend itself around the world.
\end{abstract}

Key words: Graphic environment, onomastics, adventure, linguistic globalization. 


\section{Les noms propres hispaniques au Cameroun: entre aventure et globalisation sémiolinguistique}

\section{Résumé}

L'objectif de cet article est celui de recueillir et d'analyser les noms propres hispaniques, de personne et lieu, qui sont très nombreux dans les écrits urbains du Cameroun. On a préconisé que ces anthroponymes et toponymes sont la preuve d'une migration ou aventure de mots espagnols au Cameroun, ou d'un processus de globalisation linguistique. Au-delà du code linguistique qui est importé des terres africaines, il s'agit de l'universalisation de la culture hispanique, laquelle entreprend des voies singulières pour s'étendre par le monde entier.

Mots clés: environnement graphique, onomastique, aventure, globalisation linguistique.

\section{Os nomes próprios hispânicos da República dos Camarões: entre aventura e globalização semiolinguística}

\section{Resumo}

0 objetivo deste artigo consiste em recolher e analisar os nomes próprios hispânicos de pessoa e lugar que abundam nos escritos urbanos da República dos Camarões. Tem-se postulado que ditos antropônimos e topônimos são amostra de uma migração ou aventura de palavras espanholas na República dos Camarões, ou de um processo de globalização linguística. Mais além do código linguístico que é importado a terras africanas, trata-se da universalização da cultura hispânica, a qual empreende vias singulares para estender-se pelo mundo.

Palavras chave: ambiente gráfico, onomástica, aventura, globalização linguística. 


\section{Introducción}

Existe una densa literatura sociolingüística y geolingüística que versa sobre la aventura de las lenguas y la migración de las palabras. Muchos estudios se han centrado conceptual y teóricamente en estos tipos de movimiento lingüístico, de los cuales podemos principalmente mencionar las obras de López Morales, La aventura del español en América (1998) y La andadura del español por el mundo (2010). Fuera del ámbito hispánico, la misma noción ha sido cuestionada por muchos estudiosos. Walter ha escrito un libro bastante abarcador al respecto: L'aventure des langues en Occident: leur origine, leur histoire, leur géographie (1994) y otro de alcance no menos importante, L'aventure des mots français venus d'ailleurs (1997). Junto con Baraké, Walter publica el libro titulado Arabesques. L'aventure de la langue arabe en Occident en 2006. Aquí, el término "aventura" traduce varias connotaciones: el desplazamiento, la migración, la inmigración o el viaje.

Por lo demás, abundan títulos como Alice au pays du langage (Yaguello, 1981); Les mots migrateurs (Walter, 2009); Migración de léxico regional al español americano (Bastardín Candón, 2011); La inmigración léxica (Gómez Capuz, 2005), connotaciones que, en un lenguaje a la par histórico y poético, Gaviard Dunand (2005) asume recapitular:

Estas palabras con alma viajera se aventuraron -algunas, siglos ha- más allá del territorio nacional. Incluso hoy, las hay que continuamente pasan las fronteras. No obstante, de tiempo en tiempo, el esplín las atenaza, la morriña las atormenta, entonces se vuelven a casa. Al llegar al terruño, ni siquiera se las reconoce porque cambiaron de look, jvíctimas de un remake o de un lifting linguístico! (p. 25).

En el marco de este estudio el interés gira en torno de la migración de un tipo particular de elementos lingüísticos: los nombres propios de persona y de lugar que abundan en el paisaje gráfico de Camerún. Los factores o mediaciones propiciadores, abundancia en tierra camerunesa son numerosas y abarcan los ámbitos de la tecnociencia, la literatura, las tecnologías de la información y comunicación. Como factor psico-cognitivo, la mímesis o la imitación favorecen determinadamente este proceso. 
Antes de examinar cómo se opera la migración aventurera de dichos nombres, habrá que dejar por sentado, como condición previa, su carácter hispánico. Esto es, determinar a partir de criterios lingüísticos y culturales que los mencionados antropónimos y topónimos se adecúan a la grafía española y que refieren contextos del mundo hispánico. A continuación, se abordará, respectivamente, el concepto de extranjerismo onomástico, la expansividad de los nombres de pila y de los topónimos hispanoamericanos, la flexibilidad morfosintáctica y referencial de dichos nombres.

\section{La hispanicidad de los antropónimos y topónimos}

Salvo -en cierta medida- los patrónimos y topónimos, resulta difícil fijar con exactitud el origen cultural o la nacionalidad de los nombres propios. Esta dificultad es aún aguda cuando se trata de los nombres de pila, siendo mucho más rígida y fija la naturaleza referencial de los apellidos. Y es que los antropónimos y topónimos suelen reflejar las dinámicas socio-históricas y geográficas de los pueblos que los utilizan. En la referencia onomástica se traducen las cooperaciones o relaciones bélicas, las relaciones entre el hombre y la sociedad, las migraciones, las dinastías, y las estratificaciones sociales. En este sentido,

Muchos de los antropónimos, es decir, nombres de personas, usados entre los romanos como nombres de pila, apellidos o designaciones para grandes familias, clanes u estirpes [sic], fueron copiados y adoptados en castellano cuando se trató de dar nombre a los recién nacidos, con las previas adaptaciones fonológicas, propias del sistema que permitió la evolución del latín en castellano (Mendoza Cuba y Zamudio Campos (2005, pp. 153-154).

Tres términos importantes resaltan de esta reflexión -copia, adaptación y adopción- que determinan el proceso clásico al que se someten los antropónimos. Es un proceso continuo que no se detiene nunca, ya que los pueblos o civilizaciones del mundo lo renuevan constantemente. Así que, aquí, no se pretende hacer una genealogía histórica de los términos antropo-toponímicos (Mora Monroy, 1976, p. 536) que constituyen el corpus, sino comprobar su pertenencia al vocabulario onomástico hispánico.

La hispanoproclividad (López García, 2007) de los referentes onomásticos se demostrará a partir de argumentos distintos, dependiendo de si dichos referentes son antropónimos o topónimos.

\subsection{La hispanicidad de los antropónimos}

Para enfocar mejor los nombres propios de persona desde una perspectiva migratoria o migraventurera, conviene remontarse, aunque de paso, a los orígenes gótico, 
grecolatino o árabe. La etapa hispánica del flujo migratorio nos permite, mediante un enfoque historicista y a partir de ciertos estudios, cerciorarnos de que los antropónimos censados proceden de diversas civilizaciones. De hecho, se indica en el artículo de Mendoza Cuba y Zamudio Campos (2005) que los nombres españoles como Angélica, Virginia, Augusto, Alicia, Flora, Linda, Salvador, Santos, entre otros, proceden del latín.

En nuestro corpus, los apellidos o nombres de los cuales se puede decir que son marcas identitarias (Guillorel, 2012), o que tienen un origen español, son *Lopez, *Martinez y Picasso. Los dos primeros demuestran que el sufijo '-ez' es un elemento derivacional sustantivador, a ejemplo de más casos que se pueden citar: González, Benítez, Fernández, Hernández o Sánchez. En cambio,*Angelica, Clara, Linda, Serena, Salvador y Marina forman parte del léxico común, cuyo tratamiento lexicográfico descansaría en la descripción lingüística. En otros nombres se identifica, de manera clara, la partícula '-ito' que expresa el diminutivo en español: Anita, Barbarita, Benito, Pepito, *Frankita, Rosita. También es común entre los hispanos el uso de 'don', tratamiento de respeto que se antepone a los nombres masculinos de pila. Sirvan de ilustración ejemplos como Don *Simon, Don Carlos, Don Miguel, *[Don Victoria]. Asimismo, los nombres como Carlos, Santos, Antonio, Francisca, Franco y Pablo son de origen español por su forma ortográfica.

Por lo demás, es posible hablar de la popularidad de ciertos nombres de pila en la historia, lo cual hace que algunos de ellos se transformen en apellidos (Kohoutková, 2009 , p. 21), como postular la diversidad de origen de los mismos. De hecho, los demás nombres del corpus han sido utilizados invariablemente por cameruneses de cultura francófona 0 anglófona. Hemos hablado de palabras viajeras en este trabajo; los nombres de pila tienen la capacidad de penetrar en cualquier cultura, ya manteniéndose intactos, ya obedeciendo al material fónico de las lenguas de acogida. Otra vez, Kohoutková (2009, pp. 39-44) atribuye diversos orígenes a los mismos nombres españoles: pueden ser de origen latino, hebreo, germano, griego, romance, vasco, etc.

\subsection{La hispanicidad de los topónimos}

Tratándose de los topónimos, su hispanicidad es indudable en la medida en que designan realidades geográficas, pero esta inherencia tiene que relativizarse, ya que el topónimo puede también ser un designador flexible en tanto que mediador discursivo u organizador memorial. A este respecto, las reflexiones de Paveau (2008) son bastante pertinentes y explicativas:

Dans une perspective discursive qui privilégie la mémoire et la cognition socioculturelle, le toponyme n'accomplit pas seulement une dénomination géographique, mais dessine des cheminements sémantiques complexes, contingents et parfois 
originaux, à travers les cadres culturels, identitaires, affectifs et mémoriels d'un sujet ou d'un groupe. Au sein d'une approche des faits langagiers et discursifs qui articule discours et cognition, le toponyme (comme tout nom propre d'ailleurs) peut être envisagé comme un lieu de mémoire discursive et un organisateur socio-cognitif permettant aux locuteurs de construire une histoire collective. Il tient en effet une place importante parmi les éléments qui constituent des lignées discursives, entendues comme des configurations sémantiques transmises par les locuteurs-prédécesseurs à partir de cadres prédiscursifs collectifs (Paveau, 2006). Le toponyme est un des « agents de transmission » qui inscrivent dans les discours le fil de ces lignées (p. 23-24).

Dos ideas directrices se desprenden de esta reflexión. Por una parte, se reconoce que existe una relación referencial directa entre el topónimo y la realidad física, entre el nomen y el topos. Integran esta categoría los siguientes nombres de país, región y ciudad:

(1) Las Vegas

(2) $L$ * *Panama

(3) Colombia

(4) Sacramento bar

(5) El paso bar

(6) *Barçelona fils du pays

(7) El Cuba *Guantanamo center

(8) El *rio de plata snack bar

(9) Santiago Complexe

(10) Santo domingo

Además de las grafías y estructuras que se adecúan a los principios ortográficos y morfológicos de la lengua española, los topónimos referidos designan universos geográficos hispánicos. Se alude de modo claro a España con el ejemplo (7), al subcontinente hispanoamericano mediante $L e$ *Panama, Colombia, El *rio de la plata snack bar, etc. y al sur de los Estados Unidos por medio de Las Vegas, El paso bar y Sacramento bar. "Santiago Complexe" constituye un ejemplo equívoco porque puede designar tanto Santiago de Compostela (España) como Santiago de Chile, de Cuba o Argentina (Hispanoamérica).

Por otra parte, los mismos nombres pierden parte de su opacidad referencial, y cobran el carácter de designador flexible. Esta flexibilidad es tributaria del proceso de discursivización que sufren los nombres propios, proceso que inhibe en ellos parte de su valor indicial para hacerles revestir valores conceptuales susceptibles de cambiar en función de los contextos. Los mecanismos discursivos operados son de doble naturaleza. Por un lado, vienen indicados por elementos linguiístico-textuales, es decir, términos o 
expresiones en lenguas francesa o inglesa que funcionan, ya como determinante, ya como adyacente. Los ejemplos siguientes, constituidos de enunciados bilingües pueden servir de ilustración: Le *Panama, Sacramento bar, El paso bar, *Barçelona fils du pays, El Cuba *Guantanamo center, El *rio de plata snack bar, Santiago Complexe.

Por otro lado, el segundo mecanismo de puesta en discurso de los nombres propios -lo cual contribuye en romper el carácter de referencia directa- es de índole contextual. En efecto, la transposición de los topónimos ajenos en lo local es un fenómeno puramente discursivo que cristaliza los imaginarios de ciertos cameruneses. De hecho, la importación de los nomen no se acompaña de la transferencia concreta del topos. El intento hic et nunc de re-creación de los lugares extranjeros (países, regiones, ciudades) se inscribe en la dimensión utópico-idealista de los individuos y participa de sus viscerales aspiraciones o expectativas.

Por lo demás, existen otros dos fenómenos que contribuyen en discursivizar los nombres propios de persona y de lugar. Primero, su flexibilidad morfosintáctica, que consiste en diversos mecanismos estructurales como la determinación y la adyacencia. El único caso de determinación es $L e$ *Panama, pero son numerosos los de adyacencia. Se observan fenómenos de cualificación por yuxtaposición, lo cual remite al modelo sintáctico de la lengua inglesa que suele emplearse en los discursos publicitarios. Se yuxtaponen, por ejemplo, dos elementos o secuencias nominales, atribuyéndose al segundo la función de complemento de nombre o de adjetivo. La mayoría de los datos ilustran este argumento porque constituyen enunciados con función publicitaria. Segundo, el criterio discursivo de los nombres propios estudiados tiene que ver con su significado. Notamos que los nombres propios se usan como si fueran nombres comunes, multiplicándose los contextos de denotación o referencia. Indistintamente, un bar, una tienda, un restaurante, un hotel, un taller de costura o peluquería, etc. pueden llevar cualquiera de los antropónimos o topónimos, sin que haya relación motivada entre el nombre y la actividad o estructura.

\section{La propagación de los nombres de pila hispánicos}

Según Ozaeta Gálvez (2002, p. 235), el estudio de los nombres de persona ha discurrido principalmente por dos vías; la primera de ellas, de carácter filológico, considera su origen, formación, clasificación, propagación y distribución, y la segunda, de naturaleza filosófica, se ocupa de la espinosa cuestión de su capacidad referencial, que plantea si los nombres son o no portadores de sentido. En el marco de este apartado explotamos la primera vía de la que habla Ozaeta Gálvez, postulando que los nombres de pila de tinte hispánico se propagan de modo espectacular por el mundo en general y por el territorio camerunés en particular. Buena muestra de ello: 
Los apellidos españoles están presentes en los cinco continentes a través de centenares de millones de personas. Es posible localizar hoy en día con un mismo apellido a multitud de familias de las más diversas razas y condiciones. Este hecho cuestionará de por si la creencia tan extendida en todos los ámbitos consistente en que usar un determinado apellido confiere un parentesco universal con todos los demás portadores e incluso que se puede conocer el origen familiar con solo buscar el apellido en los tratados de genealogía (Alfaro de Prado Sagrera (2008, p. 1).

Sin embargo, el autor reconoce que "los mecanismos de expansión de los apellidos han permanecido sumidos en un conjunto de tópicos e informaciones dispersas" (p. 2) y se propone avanzar en la cuestión para mejor "plantear visiones de conjunto". Solo que, en su estudio, él mismo confunde el concepto de transmisión con el de expansión. Desde el punto de vista genealógico es el fenómeno de transmisión el que explica la propagación de los nombres propios de persona. Este tipo de extensión puede tratarse de vertical y se aplica en el modelo de transmisión familiar de que habla Alfaro de Prado Sagrera. Ahora bien, existe otro modo de expansión horizontal que se asemeja más o menos al segundo modelo de nuestro estudioso y que no tiene nada que ver con la idea de transmisión.

La expansión onomástica de que hablamos en este estudio es de índole discursiva porque la existencia de antropónimos en el entorno gráfico de Camerún no se debe exclusivamente a que la gente los porta como tal. Son nombres portados por gentes reales 0 irreales, presentes o ausentes; nombres creados a partir de otros nombres (Albert $=>$ Alberto, François => Franco), nombres vistos en fuentes documentales, televisivas, cibernéticas o cinematográficas. De hecho, su importación y expansión explotan los medios masivos de comunicación y las llamadas TIC, las cuales se han erigido estas décadas en mediadores culturales eficaces. Cabe precisar a este respecto que muchos antropónimos hispánicos han sido transpuestos en el paisaje gráfico de Camerún a partir de los campeonatos de fútbol o a través de las telenovelas latinoamericanas. Asistimos a un fenómeno consistente en que los cameruneses se apropian los nombres de estrellas futbolísticas o de personajes cinematográficos no solo por fines discursivos, sino para designar las actividades y estructuras socioeconómicas o socioculturales. No es de extrañar que, hablando de los referentes culturales, Wennergren (2010) considere los nombres propios como espejos culturales, ya que, en el caso de Camerún, contribuyen en una interacción concreta entre diversos universos culturales.

Partiendo de los datos disponibles y presentados en el trabajo citado, se evidencia que -como ya se ha mencionado anteriormente- son los nombres de pila los que más se propagan. Representan más del 95\% de los antropónimos recogidos y se presentan 
bajo diversas formas: nombres simples (Pedro, Roberto, Clara), nombres compuestos o precedidos de una fórmula de tratamiento (Carlos Santos, Don Miguel, Don *Simon, etc.), nombres de varón (Julio, Armando, Augusto) y de hembra (Claudia, Cecilia, Sandra) formas diminutivas (Anita, Barbarita, *Pakito). En comparación con los apellidos, los nombres de pila son más dinámicos porque no suelen designar patronos. Aunque no es nulo, su valor 0 anclaje antropo-sociológico parece superficial. En ciertas sociedades de religión católica, el nombre de pila se atribuye con motivo del bautismo, sacramento que puede intervenir a cualquier edad del individuo; lo cual, en ciertos casos, constituye una denominación diferida en la medida en que el individuo ya se ha fraguado parte de su identidad. Así que la elección y atribución de los nombres de pila es un proceso que emprende las vías del conformismo, de la moda y del locus communis (Méchin, 2006). Hay en el mundo más personas homónimas que comparten los mismos nombres de pila, los cuales se sacan de las agendas o repertorios de nombres y se atribuyen de modo más o menos arbitrario a las personas. Mas aún, los nombres de pila son los menos propios de los nombres propios. A causa de alta propagación -lo que lleva a Tshiala (2011) a hablar de "la confusión générée par la croissante homonymie prénominale" (p. 38) -los nombres de pila no difieren tanto de los nombres comunes-.

Por lo demás, cabe precisar que los antropónimos que se usan en Camerún son la cara visible de un fenómeno cultural subyacente. En el marco de una tesis doctoral en que Hatolong (2014) aborda la noción del discurso epilinguístico, se nota que los cameruneses tratan la lengua española de romántica, melódica y poética. Estas valoraciones subjetivas cristalizan un conjunto de prácticas y representaciones sociolingüísticas, a la par que demuestran cómo la cultura hispánica se consume en Camerún. De hecho, los antropónimos del corpus funcionan como nombres de marca o de producto que lleva el universo cultural panhispánico. De ahí que la migraventura onomástica que se estudia en este trabajo se inscriba cabalmente en el fenómeno de globalización lingüística en particular y de globalización cultural en general. Por consiguiente, la reflexión adhiere a la idea bastante extendida de que la lengua es el vehículo o mediador de la identidad cultural. Y tratándose de la onomástica, no puede ser aislada del tema de identidad, ya que resultan ser intrínsecos y de alguna forma se merecen el uno al otro. Al respecto, se menciona que:

La onomástica, además del estudio etimológico de los nombres, ahora relacionado con las influencias y los préstamos culturales entre distintos pueblos, etnias y culturas a lo largo del tiempo y del espacio, nos indica también la pervivencia de tradiciones, y todo ello le proporciona una apariencia de intemporalidad" (Ballesteros Díez, 2004, p. 28). 


\section{La propagación de los topónimos latinoamericanos}

Dentro de los nombres propios hispánicos que se inscriben en el paisaje de Camerún abundan los topónimos latinoamericanos. Otra vez, su expansión se debe a que quedan utilizados como lexías ordinarias dotadas de valores conceptuales que se actualizan en el habla o discurso (Shokhenmayer, 2009). En este caso, los topónimos dejan de referirse a lugares físicos para designar topos simbólicos a los cuales se asocian diversas representaciones e imaginarios. Así, aparte de funcionar como nombres de personajes novelescos que se discursivizan por ficcionalizarse (Ouhibi-Ghassoul, 2011), los topónimos latinoamericanos se parecen a cualquier extranjerismo lingüístico que se integra en el léxico común y se usa de modo contextual por parte de los locutores.

Hablando de las representaciones o imaginarios, notamos que los latinoamericanismos traducen dos dinámicas socioculturales que, ya se confrontan a causa de ciertas divergencias históricas, ya se asimilan por los desafíos futuristas que tienen en común. Por una parte, las culturas latinas de Suramérica impactan de modo concreto sobre el cotidiano de los cameruneses por medio de las telenovelas. Por otra parte, las culturas sincréticas del sur de Estados Unidos se transparentan en Camerún a través de las aludidas telenovelas y otras vías que sirven de vehículo a la cultura norteamericana. De hecho, el uso en el entorno gráfico de Camerún de los referentes toponímicos como Los Ángeles, Las Vegas, Sacramento, etc. materializan el universalismo o cosmopolitismo estadounidenses.

Por tanto, contrariamente a España que poco se importa a África en general y a Camerún en particular desde el punto cultural -salvo su fútbol que ocupa un lugar de relevancia en el mundo-, el área latina del continente americano se hace cada vez más visible. Lo cual pone en tela de juicio el porvenir único de la cultura hispánica y de la lengua española. Si "al español le sienta bien la globalización y a diferencia de otras lenguas (singularmente el francés), no parece necesitar de excepción cultural alguna" (Lamo De Espinosa, 2014, p. 3), la misma lengua-cultura necesita aspectos vitales como la creatividad, la pluralidad, la identidad y la soberanía cultural (Torres Robles, 2006, p. 144). Los desafíos de esta cultura hispánica y del futuro del español (López Morales, 2006) se retarán en el continente americano.

\section{Conclusión}

El objetivo de este estudio ha sido reflexionar sobre la dinámica de los antropónimos y topónimos que los cameruneses inscriben en su paisaje urbano. Se ha mencionado, aunque de manera sucinta, los factores de mediación que se han utilizado; los cuales son 
el fútbol, la internet, el cine, el viaje y diversos tipos de documentos. Los conceptos de migración y aventura que se han utilizado como hipótesis caben adecuadamente porque, salvo el estatuto de lengua extranjera que se asigna al español en Camerún, no hay en este país una verdadera comunidad lingüística que utilice el castellano como lengua de comunicación. La globalización lingüística conviene también al mecanismo, ya que se inscribe en un fenómeno global de expansión que diversos sociolingüistas estudian estas décadas. Mas aún, más allá de la lengua que se propaga a través de sus lexías, se trata del universalismo de la cultura hispánica que, en sus dos vertientes peninsular y americano, se importa hacia tierras africanas para interactuar con las culturas locales. A la expansión de los nombres propios contribuye eficazmente su uso discursivo, enmarcando así el fenómeno dentro de dimensiones representacionales o socio-cognitivas.

\section{Referencias bibliográficas}

Alfaro De Prado Sagrera, A. (2008). Descripción de las múltiples y complejas vías por las que se expandieron los apellidos españoles a lo largo de la Historia. Boletín electrónico de la Academia Costarricense de Ciencias Genealógicas, $\mathrm{N}^{\circ}$ 87, pp. 1-21.

Ballesteros Díez, J. A. (2004). Onomástica y mentalidades en el siglo XVI. Espacio, Tiempo y Forma $\mathrm{N}^{\circ} 17$, pp. 27-57.

Bastardín Candón, T. (2011). Migración de léxico regional al español americano. La crónica de fray Bernardino de Sahagún. Boletín de Filología Vol. XIVI, N 2, pp. 11-34.

Gaviard Dunand, M-D. (2005). Les emprunts linguistiques. Encuentro $\mathrm{N}^{\circ} 15$, pp. 25-31.

Gómez Capuz, J. (2005). La inmigración léxica. Madrid: Arco/Libros.

Guillorel, H. (2012). Onomastique, marqueurs identitaires et plurilinguisme. Les enjeux politiques de la toponymie et de l'anthroponymie ». Droit et cultures. Recuperado dehttp:// droitcultures.revues.org/2780

Hatolong Boho, Z. (2014). El español en el paisaje semio-lingüístico de Camerún: entre prácticas y representaciones, tesis doctoral, Maroua: Université de Maroua (Cameroun).

Kohoutková, H. (2009). Los antropónimos españoles con especial atención a los nombres de pila, tesis de Máster, Masarykova: Universidad de Masarykova.

Lamo De Espinosa E. (2014). El futuro de la lengua española. $A B C$. 12/01/2014.

López García Á. (2007). La lengua española y sus tres formas de estar en el mundo. Anuario del Instituto Cervantes 2006-2007, pp. 471-475. 
López Morales, H. (1998). La aventura del español en América. Madrid: Espasa Calpe.

López Morales, H. (2006). El futuro del español. Instituto Cervantes, Enciclopedia del español en el mundo, pp. 476-491. Barcelona: EGEDSA.

López Morales, H. (2010). La andadura del español por el mundo. Buenos Aires: Taurus.

Méchin, C. (2006). La fonction prénominale. Recherches sociologiques et anthropologiques. Recuperado dehttp://rsa.revues.org/579

Mendoza Cuba, A. Zamudio Campos R. (2005). Nombres propios de procedencia latina. Escritura y Pensamiento $\mathrm{N}^{\circ} 17$, pp. 153-182.

Mora Monroy S. C. (1976). Breve estudio sobre apellidos y nombres propios de persona en Colombia. Thesaurus Vol. XXXI, $\mathrm{n}^{\circ}$ 3, pp. 536-560.

Ouhibi-Ghassoul, N. (2011). Approche du personnage romanesque par le biais de l'onomastique: Timimoun de Rachid Boudjedra. Resolang N 5, pp. 119-125.

Ozaeta Gálvez, M. R. (2002). Los antropónimos: nociones teóricas y modalidades de transferencia (francés-español). Epos $\mathrm{N}^{\circ}$ XVIII, pp. 233-255.

Paveau, M-A. (2008) . Le toponyme, désignateur souple et organisateur mémoriel. L'exemple du nom de bataille. Mots. Les langages du politique. Recuperado de <mots.revues.org/13102>.

Shokhenmayer, E. (2009). Champs associatifs des noms propres et mécanismes de la comprébension textuelle, tesis doctoral, Université Paris Ouest Nanterre la Défense.

Torres Robles, Al. (coord.)(2006). El español activo cultural y valor económico creciente, I Acta Internacional de la Lengua Española, San Millán de la Cogolla (La Rioja-España), del 26 al 29 de octubre de 2006.

Tshiala, L. (2011). La dynamique des anthroponymes chez les Ding de la République Démocratique du Congo (1885 - 1960), tesis doctoral, Université de Neuchâtel.

Walter, H. (1996). L'aventure des langues en Occident: leur origine, leur histoire, leur géographie. París: Robert Laffont.

Walter, H. (2006). Arabesques: L'Aventure de la langue arabe en Occident. París: Robert Laffont.

Walter, H.(2008). La langue française et les mots migrateurs. Synergies Italie $\mathrm{N}^{\circ} 4$, pp. 15-21.

Walter, H. (2009). Les mots migrateurs : les tribulations du français en Europe. París: Seuil.

Yaguello, M. (1981). Alice au pays du langage. Pour comprendre la linguistique. París: Seuil. 


\section{Anexo}

\begin{tabular}{|c|c|c|c|}
\hline \multicolumn{3}{|c|}{ Antropónimos } & Topónimos \\
\hline $\begin{array}{l}\text { - Ets Don *Simon } \\
\text { - Café bar Bernardo } \\
\text { - Barbarita-bar } \\
\text { - Club pichichi } \\
\text { - Manuela-boutique } \\
\text { - Sosso Daniel*Vertigo } \\
\text { - *[Don Victoria] } \\
\text { - Chez *Frankita } \\
\text { - Guele Francisca Brigitte } \\
\text { - Chez Odilia Coiffure } \\
\text { - Parfumerie Armando } \\
\text { - Miranda Coiffure } \\
\text { - Ma Rosa Boulevard } \\
\text { - Augusto électronique } \\
\text { - Alicia Academic Julio Bar } \\
\text { - Restaurant-Bar Chez Clara } \\
\text { - Victoria Blue Nile } \\
\text { - La Cave Don Miguel } \\
\text { - *insfins } \\
\text { *Armando Construction }\end{array}$ & $\begin{array}{l}\text { - *Martinez bar } \\
\text { - Salvador salon } \\
\text { de coiffure } \\
\text { - *Lopez } \\
\text { - Picasso IBA } \\
\text { - Valentino } \\
\text { - Don Carlos } \\
\text { - Udip Emilia } \\
\text { - Che Cecilia } \\
\text { - Diana Bib } \\
\text { - Fru Claudia } \\
\text { - Julio Bar } \\
\text { - Franco bar } \\
\text { - Franca Coiffure } \\
\text { - Flora Coiffure } \\
\text { - Antonio Coiffure } \\
\text { - Ets PN Pablo } \\
\text { - Awanjong Linda } \\
\text { - Pepito coiffure } \\
\text { - Carlos Santos }\end{array}$ & $\begin{array}{l}\text { - *Christiana Hotel } \\
\text { - *Edouardo } \\
\text { - Virginia Fashion } \\
\text { - Roberto } \\
\text { - Menyo Lucas } \\
\text { - Anita Motel } \\
\text { - Benito Network } \\
\text { - Avec Pascual } \\
\text { - Décor } \\
\text { - Pedro } \\
\text { - Sandra Telecom } \\
\text { - Francisco hoping } \\
\text { - Patricia computer } \\
\text { - *Angela Business } \\
\text { - Hotel Serena Pãlace } \\
\text { - *Angelicadress } \\
\text { - Pakito } \\
\text { - *Martinez }\end{array}$ & $\begin{array}{l}\text { - Eldorado + plus } \\
\text { - Welcome to Santa } \\
\text { *Barbara } \\
\text { - Las Vegas } \\
\text { - Le *Panama } \\
\text { - Las Vegas city } \\
\text { - Colombia } \\
\text { - Sacramento bar } \\
\text { - San-Francisco salón } \\
\text { - Los *Angeles } \\
\text { - GIC de santé Santa Cruz } \\
\text { - Casa blanca bar } \\
\text { - El paso bar } \\
\text { - Las palmas bar } \\
\text { - *Barçelonafils du pays } \\
\text { - El Cuba *Guantanamo } \\
\text { center } \\
\text { - El *río de plata bar } \\
\text { - *Casablanca } \\
\text { - Santiago Complexe } \\
\text { - Santo Domingo }\end{array}$ \\
\hline
\end{tabular}

